\title{
Discussion on numerical simulation method of salt-resistant polymer flooding in three types of reservoirs
}

\author{
Jiqiang Chen \\ Geological Brigade of the Fourth Oil Production Plant of Daqing Oilfield Co., Ltd., Heilongjiang, Daqing 163511, China.
}

\begin{abstract}
According to the development characteristics of three types of reservoirs, this paper analyzes the main characteristics of salt-resistant polymer, and forms a highly targeted setting method for the key parameters of numerical simulation. At the same time, according to the actual situation of the salt-resistant test area, different injection parameter schemes are predicted, and the optimal design scheme is determined. Finally, the numerical simulation method of salt-resistant polymer flooding in three types of reservoirs is preliminarily formed.
\end{abstract}

Keywords: Three types of oil layers; Numerical simulation; Salt-resistant polymert

\section{Introduction}

Chemical flooding numerical simulation has many adjustment parameters, complex adjustment methods and difficult prediction. Salt-resistant polymer flooding in three types of reservoirs has the characteristics of poor reservoir development and special polymer, which further increases the difficulty of numerical simulation. Therefore, the numerical simulation method of saltresistant polymer flooding in three types of reservoirs is discussed to ensure the prediction accuracy of development effect in the test area.

\section{Set method for forming shear coefficient}

In the numerical simulation of chemical flooding, the sensitivity of thick viscosity parameters is the strongest, which has a great influence on the water cut decline rate, the minimum water cut and the final fitting result, and the polymer will also be subjected to pore shear when migrating in the reservoir. The viscosity of polymer will lose a part, which must be considered in numerical simulation. The setting of shear coefficient is related to the rationality of thick viscosity parameters AP1, AP2 and AP3 (Formula 1), so the setting method of shear coefficient plays a vital role in the final prediction accuracy. The results of laboratory experiments show that the salt-resistant polymer has strong salt resistance, so the thick viscosity curve measured under the condition of high salinity brine should be selected when calculating the thick viscosity parameters (Figure 1); At the same time, the experimental results show that the shear resistance of salt-resistant polymer has no advantage compared with ordinary polymer (Table 1), so the setting of shear coefficient of this polymer can follow the law of other ordinary polymers.

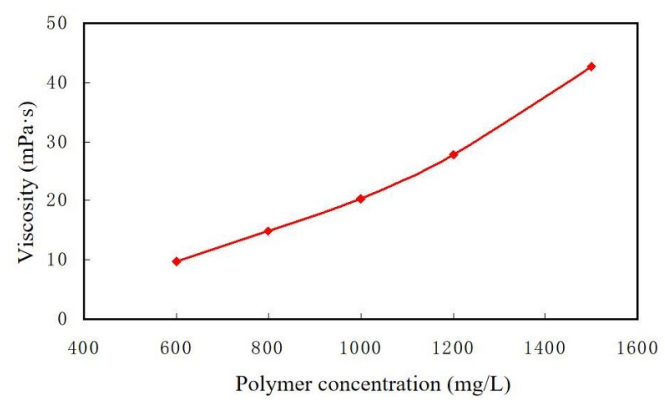

Figure 1Thick viscosity curve of salt-resistant polymer

Table 1 Evaluation results of shear resistance of salt-resistant polymer

\begin{tabular}{|c|c|c|c|c|}
\hline \multirow{2}{*}{ Polymer } & \multicolumn{2}{|c|}{$\begin{array}{c}\text { Salt-resistant } \\
\text { polymer }\end{array}$} & \multicolumn{2}{c|}{ Ordinary 8 million } \\
\cline { 2 - 5 } & $\begin{array}{c}1000(\mathrm{mg} \\
\mathrm{L})\end{array}$ & $\begin{array}{c}1400(\mathrm{mg} \\
/ \mathrm{L})\end{array}$ & $\begin{array}{c}1000(\mathrm{mg} \\
/ \mathrm{L})\end{array}$ & $\begin{array}{c}1400(\mathrm{mg} \\
/ \mathrm{L})\end{array}$ \\
\hline $\begin{array}{c}\text { Before } \\
\text { shearing(mP } \\
\mathrm{a} \cdot \mathrm{s})\end{array}$ & 17.6 & 32.6 & 11.7 & 19.5 \\
\hline $\begin{array}{c}\mathrm{After} \\
\text { shearing,(m } \\
\text { Pa·s) }\end{array}$ & 9.6 & 20.3 & 8.5 & 14.3 \\
\hline $\begin{array}{c}\text { Viscosity } \\
\text { retention } \\
\text { rate(\%) }\end{array}$ & 54.5 & 62.3 & 72.9 & 73.3 \\
\hline
\end{tabular}

The shear action of polymer in reservoir is mainly produced when polymer passes through reservoir pores.

\footnotetext{
* Corresponding author: chenjiqiang@nepu.edu.cn
} 
The median particle size is the main parameter reflecting the pore structure. By studying the rule of shear coefficient and median particle size of the previous chemical flooding block tracking model, it is found that there is an approximate linear relationship between them (Figure 2). The reasonable initial value of shear coefficient can be accurately calculated by using this regression formula.

$$
\mu_{p}^{0}=\mu_{w}\left(1+\left(A_{P 1} C_{P}+A_{P 2} C_{P}^{2}+A_{P 3} C_{P}^{3}\right) C_{S E P}^{S_{P}}\right)(1)
$$

Among them: $\mu_{p}^{0} \longrightarrow$ Viscosity of polymer solution at zero shear rate;

$C_{P} \longrightarrow$ Polymer concentration;

$C_{S E P}-$ Effective salt content in aqueous phase;

$S_{P} \longrightarrow$ Test constant;

$\mu_{w}-$ Water viscosity.

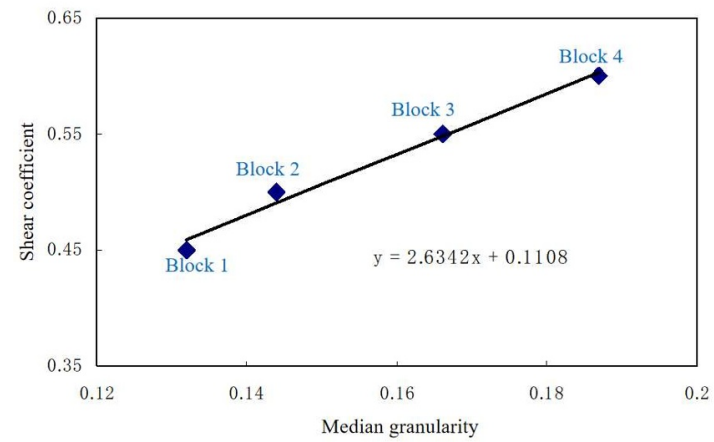

Figure 2 Relationship curve between median particle size and shear coefficient

\section{Determine the fitting method of oil and water well measures}

Compared with the main oil layer, the target layer in the salt-resistant test area is relatively poor in development (Table 2). With the deepening of polymer injection, the injection-production capacity of the test area will gradually decline, and the test area will inevitably improve the injection-production capacity by means of measures. It is necessary to simulate this phenomenon in the process of digital-analog prediction, so that the whole prediction process is closer to the actual production situation. Compared with the previous three types of oil layer blocks, the oil layer development status of the test area and block $\mathrm{A}$ is relatively close (Table 3 and Table 4); In the process of measure prediction, the oil layer development status in the test area is analyzed in depth, and combined with the actual oil layer production status of Block A (Table 5), 44 wells and 35 wells of oil-water well measures are simulated in the low water cut period and the water cut recovery period of the test area respectively.

Fracturing measures mainly improve the percolation capacity of the target layer by means of fracture-making. In numerical simulation, this phenomenon is mainly simulated by improving the conductivity of oil layer.
Permeability is the main parameter reflecting the percolation capacity of oil layer. The permeability improvement multiple of the post-fracturing measures layer can be approximately defined as the conductivity improvement multiple. Different developed reservoirs have different permeability improvement before and after measures. If the improvement multiples of the measures horizon conductivity are assigned to an empirical coefficient, the measures phenomenon will not be simulated realistically, which will eventually affect the prediction accuracy. Therefore, a scientific calculation method must be applied to determine the conductivity coefficient. The regression curve of permeability after fracturing (Figure 3 ) is summarized by studying the results of previous measures in polymer injection block. The permeability improvement times after measures can be calculated by applying the permeability before fracturing and regression formula, and the scientific conductivity coefficient can be obtained.

Table 2 Basic situation of salt resistance test area

\begin{tabular}{|c|c|c|c|c|c|c|c|c|c|}
\hline \multirow[b]{2}{*}{$\begin{array}{l}\text { P } \\
r \\
\text { oj } \\
\text { e } \\
\mathrm{ct} \\
\mathrm{s}\end{array}$} & \multirow[b]{2}{*}{$\begin{array}{c}\text { Dev } \\
\text { elo } \\
\text { pm } \\
\text { ent } \\
\text { hori } \\
\text { zon }\end{array}$} & \multirow[b]{2}{*}{$\begin{array}{l}\text { in } \\
\text { je } \\
\text { ct } \\
\text { io } \\
\text { n } \\
\text { w } \\
\text { el } \\
1\end{array}$} & \multirow[b]{2}{*}{$\begin{array}{l}\text { Pr } \\
\text { od } \\
\text { uct } \\
\text { ion } \\
\text { we } \\
\text { ll }\end{array}$} & \multicolumn{3}{|c|}{ Development } & \multicolumn{3}{|c|}{ Shoot open } \\
\hline & & & & $\begin{array}{c}\text { Sa } \\
\text { nd } \\
\text { st } \\
\text { on } \\
\mathrm{e} \\
(\mathrm{m} \\
\text { ) }\end{array}$ & $\begin{array}{l}\text { Ef } \\
\text { fe } \\
\text { ct } \\
\text { iv } \\
\text { e( } \\
\text { m } \\
)\end{array}$ & $\begin{array}{c}\text { Per } \\
\text { me } \\
\text { abil } \\
\text { ity( } \\
\mathrm{mD} \\
\text { ) }\end{array}$ & $\begin{array}{c}\text { Sa } \\
\text { nd } \\
\text { st } \\
\text { on } \\
\text { e } \\
\text { (m } \\
\text { ) }\end{array}$ & $\begin{array}{c}\text { Ef } \\
\text { fe } \\
\text { ct } \\
\text { iv } \\
\text { e( } \\
\text { m } \\
)\end{array}$ & $\begin{array}{c}\text { Per } \\
\text { me } \\
\text { abil } \\
\text { ity( } \\
\mathrm{mD} \\
\text { ) }\end{array}$ \\
\hline $\begin{array}{l}\text { W } \\
\text { h } \\
\text { ol } \\
\text { e } \\
\text { re } \\
\text { gi } \\
\text { o } \\
\text { n }\end{array}$ & $\begin{array}{c}\mathrm{Sa} \\
\mathrm{II} 11 \\
\sim \\
16\end{array}$ & $\begin{array}{l}4 \\
1\end{array}$ & 41 & $\begin{array}{c}9 . \\
8\end{array}$ & $\begin{array}{l}5 . \\
2\end{array}$ & 156 & $\begin{array}{c}8 . \\
5\end{array}$ & $\begin{array}{l}5 . \\
2\end{array}$ & 179 \\
\hline
\end{tabular}

Table 3 Sandstone thickness statistical table of reservoir permeability classification

\begin{tabular}{|c|c|c|c|c|c|}
\hline \multirow{2}{*}{ Block } & \multicolumn{5}{|c|}{ Permeability classification } \\
\cline { 2 - 6 } & $<50$ & $50-100$ & $100-200$ & $200-300$ & $\geq 300$ \\
\hline Block a & 15.3 & 24.7 & 33.3 & 12.8 & 13.9 \\
\hline Block b & 30.1 & 30.1 & 24.7 & 12.3 & 2.8 \\
\hline Test area & 8.2 & 21.8 & 38.9 & 14.6 & 16.5 \\
\hline
\end{tabular}

Table 4 Statistical table of effective thickness of reservoir permeability classification

\begin{tabular}{|c|c|c|c|c|c|}
\hline \multirow{2}{*}{ Block } & \multicolumn{5}{|c|}{ Permeability classification } \\
\cline { 2 - 6 } & $\begin{array}{c}<5 \\
0\end{array}$ & $\begin{array}{c}50- \\
100\end{array}$ & $\begin{array}{c}100- \\
200\end{array}$ & $\begin{array}{c}200- \\
300\end{array}$ & $\begin{array}{c}\geq 30 \\
0\end{array}$ \\
\hline Block a & $\begin{array}{c}10 . \\
7\end{array}$ & 20.2 & 30.3 & 16.5 & $\begin{array}{c}22 . \\
3\end{array}$ \\
\hline Block b & 13 & 30.5 & 30.5 & 19.8 & 6.2 \\
\hline Test area & 1.4 & 13.4 & 30.8 & 20.3 & $\begin{array}{c}34 . \\
1\end{array}$ \\
\hline
\end{tabular}


Table 5 Statistical table of production status of oil layer a in block

\begin{tabular}{|c|c|c|c|c|c|c|c|c|c|}
\hline \multirow{3}{*}{ Stage } & \multicolumn{7}{|c|}{ Deposition unit } \\
\cline { 2 - 10 } & S2 & S2 & S2 & S & S & S & S & S2 & S \\
& 11 & 11 & 11 & 2 & 2 & 2 & 2 & 15 & 2 \\
& -1 & -2 & -3 & 1 & 1 & 1 & 1 & -1 & 1 \\
\hline Blank & & & & 7 & 6 & 4 & 5 & & 5 \\
water & .6 & 46 & 47 & 7 & 0 & 3 & 2 & 31 & 9 \\
drive & .6 & .8 & .4 &. &. &. &. & .0 &. \\
\hline Pre- & & & & 2 & 0 & 0 & 3 & & 3 \\
polymer & .9 & 50 & 75 & 9 & 5 & 5 & 1 & 18 & 9 \\
flooding & & & & .0 &. &. &. & .7 &. \\
\hline \multirow{2}{*}{ Ternary } & 69 & 45 & 81 & 6 & 5 & 8 & 1 & 40 & 1 \\
stage & .2 & .9 & .6 &. &. &. &. & .9 &. \\
& & & & 7 & 8 & 9 & 0 & & 9 \\
\hline
\end{tabular}

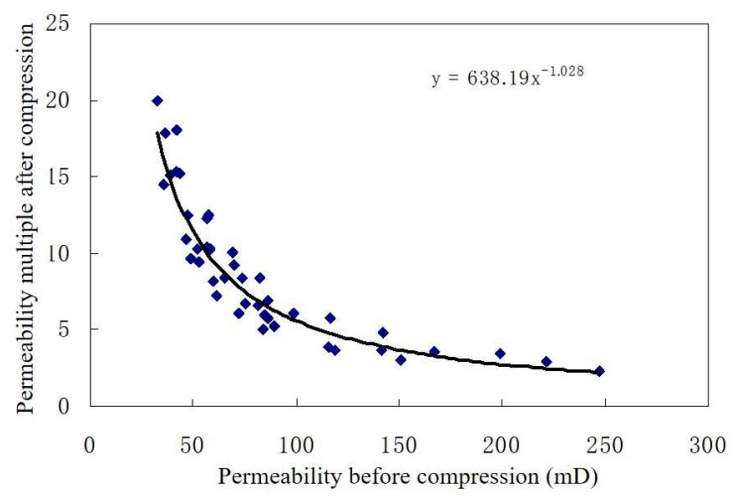

Figure 3 Regression curve of permeability after fracturing

\section{Optimized injection parameter scheme}

The target horizon of the salt-resistant test area is three types of oil layers. In order to maintain the injectionproduction capacity of the test area and the uniform production of each horizon, the rationality of injection parameter design is the key. The injection-production well spacing in the test area is $125 \mathrm{~m} \mathrm{~m}$. According to the calculation formula of injection rate (Formula 2), the reasonable injection rate in the test area is $0.18 \sim 0.20$ $\mathrm{PV} / \mathrm{a}$; The design of injection concentration is the core work of the whole injection parameter design. In the past, the injection parameter matching template was established according to the matching of common polymer in the main oil layer, which could not be directly applied in the test area, so the parameter matching template of salt-resistant polymer was established (Figure 4). According to the parameter matching template, in order to ensure the smooth injection in the test area, the upper limit of injection concentration should be $1200 \mathrm{mg} / \mathrm{l}$; At the same time, different injection slugs, such as single concentration and stepped concentration reduction, were designed, and seven injection parameter schemes were numerically simulated. The numerical simulation results show that the fifth scheme has the best development effect
(Table 6). In the process of numerical simulation, when the water cut in the test area rises to $96 \%$, the polymerization is stopped until the water cut in the test area rises to $98 \%$.

$$
P_{\max }=L^{2} \phi V /\left(180 N_{\min }\right)
$$

Among them, $P_{\max }-$ Maximum injection pressure at wellhead, MPa;

$L$ - Injection-production well spacing, m;

$\phi —$ Reservoir porosity, decimal;

$V$ _-Injection speed, PV/a;

$N_{\min }$ Lowest apparent water absorption index of oil layer, m3/d.m.MPa.

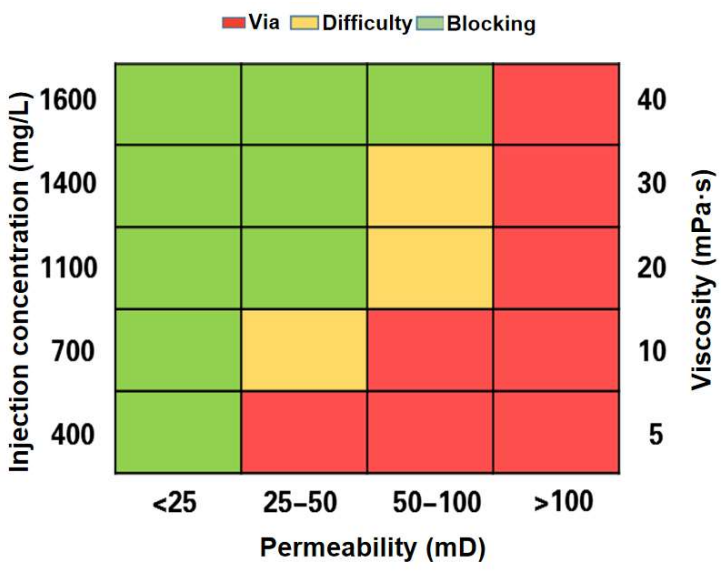

Figure 4 Parameter matching template of ds 800 polymer

Table 6 Statistical table of numerical simulation results of injection parameter scheme

\begin{tabular}{|c|c|c|c|c|c|}
\hline \multirow[b]{2}{*}{$\begin{array}{l}\text { Prog } \\
\text { ram } \\
\text { me }\end{array}$} & \multicolumn{3}{|c|}{ Injection parameters } & \multicolumn{2}{|c|}{$\begin{array}{c}\text { Mathematical } \\
\text { model prediction } \\
\text { results }\end{array}$} \\
\hline & $\begin{array}{l}\text { PV } \\
\text { numb } \\
\text { er }\end{array}$ & $\begin{array}{l}\text { Injecti } \\
\text { on } \\
\text { veloci } \\
\text { ty } \\
(\mathrm{PV} / \mathrm{a} \\
\text { ) }\end{array}$ & $\begin{array}{c}\text { Injecti } \\
\text { on } \\
\text { conce } \\
\text { ntratio } \\
\mathrm{n} \\
(\mathrm{mg} / \mathrm{L} \\
) \\
\end{array}$ & $\begin{array}{l}\text { Minimu } \\
\text { m water } \\
\text { cut } \\
(\%)\end{array}$ & $\begin{array}{c}\text { Enhanc } \\
\text { ed oil } \\
\text { recover } \\
y \\
\text { (percen } \\
\text { tage } \\
\text { points) }\end{array}$ \\
\hline 1 & 0.8 & 0.20 & 800 & 93.25 & 9.14 \\
\hline 2 & 0.8 & 0.18 & 1000 & 92.18 & 9.50 \\
\hline 3 & 0.8 & 0.16 & 1200 & 91.42 & 9.31 \\
\hline 4 & $\begin{array}{c}0.1 / 0 . \\
7\end{array}$ & $\begin{array}{c}0.16 / 0 \\
.18\end{array}$ & $\begin{array}{l}1200 / \\
1000\end{array}$ & 91.16 & 9.65 \\
\hline 5 & $\begin{array}{c}0.1 / 0 . \\
7\end{array}$ & $\begin{array}{c}0.18 / 0 \\
.20\end{array}$ & $\begin{array}{c}1000 / \\
800\end{array}$ & 91.07 & 10.37 \\
\hline 6 & $\begin{array}{c}0.1 / 0 . \\
4 / 0.3\end{array}$ & $\begin{array}{c}0.16 / 0 \\
.18 / 0 . \\
20\end{array}$ & $\begin{array}{c}1200 / \\
1000 / \\
800\end{array}$ & 91.14 & 10.19 \\
\hline 7 & $\begin{array}{c}0.05 / \\
0.6 / 0 \\
15\end{array}$ & $\begin{array}{c}0.16 / 0 \\
.18 / 0 . \\
20\end{array}$ & $\begin{array}{c}1200 / \\
1000 / \\
800\end{array}$ & 91.21 & 9.72 \\
\hline
\end{tabular}




\section{Actual application situation}

The above method is applied to the salt-resistant test area for numerical prediction. According to the results of numerical prediction (Figure 5), the lowest water cut in the test area is $91.07 \%$, the final recovery rate is $11.39 \%$, the planned salt-resistant polymer consumption is $1256.89 \mathrm{t}$, and the cumulative oil increase in the test area is estimated to be $9.24 \times 10^{4} \mathrm{t}$.

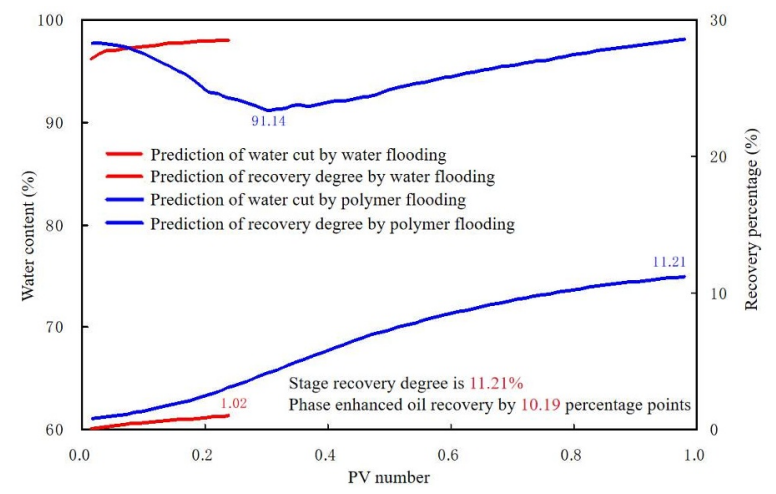

Figure 5 Figure of numerical simulation prediction results in salt resistance test area

\section{Summary}

(1) Numerical simulation prediction of polymer flooding must deeply understand the characteristics of polymer, and it is the key to ensure the prediction accuracy to set important numerical simulation parameters with scientific calculation methods;

(2) Combined with the development of oil layers in the block, it is necessary to make reasonable prediction of important measures in the future, which is a necessary method to further improve the prediction accuracy.

(3) Scientific injection parameter scheme prediction can effectively improve the rationality of numerical simulation prediction, and also improve the practical guiding significance of numerical simulation curve to field production and development.

\section{References}

1. Wang Xinhai. Determination of main parameters of numerical simulation of polymer flooding [J]. Petroleum Exploration and Development. 1990,17(3): 69-76.

2. Zhang Yanhui, Zeng Xuemei, Wang Yingbiao, et al. Numerical Simulation of Polymer Flooding in Three Types of Reservoirs in Daqing Oilfield [J]. Fault Block Oil and Gas Field, 2011, 18(2):232-234.

3. Lu kewei. parameter estimation technology and application of polymer flooding numerical simulation [A]. petroleum geology and engineering, 2013,27(1):114-116.

4. Wang Zhengbo, Wang Qiang, Ye Yinzhu, et al. History fitting method of polymer flooding with multi-parameter constraints [J]. Petroleum Exploration and Development, 2010, 18(2):216-219. 